\title{
Contents
}

\section{Part I Numerical Methods}

\section{Computational Methods for Hyperbolic Equations}

E.F. Toro .................................... 3

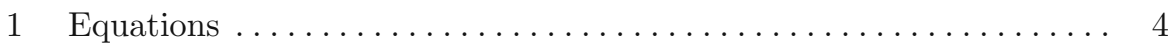

2 The Finite Difference Method ........................ 16

3 Two Riemann Solvers: HLLC and EVILIN . . . . . . . . . . . . 31

4 Non-linear Methods for Scalar Equations . . . . . . . . . . . . . 43

5 Non-linear Schemes for Hyperbolic Systems . . . . . . . . . . . . . . . 55

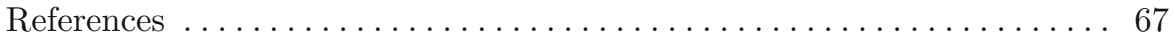

Shock-Capturing Schemes in Computational MHD

A. Mignone, and G. Bodo .............................. 71

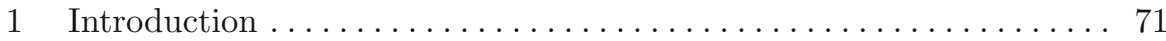

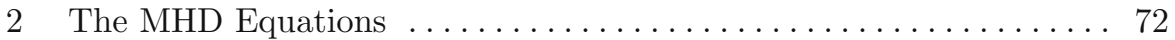

3 The Riemann Problem in MHD $\ldots \ldots \ldots \ldots \ldots \ldots \ldots \ldots \ldots \ldots$

4 The $\nabla \cdot B=0$ Condition $\ldots \ldots \ldots \ldots \ldots \ldots \ldots \ldots \ldots \ldots \ldots \ldots \ldots \ldots \ldots \ldots$

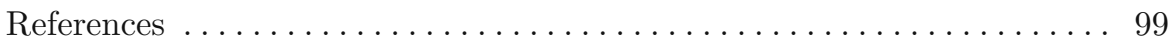

Part II Hydrodynamic and Magneto-Hydrodynamic Instabilities

\section{The Kelvin-Helmholtz Instability}

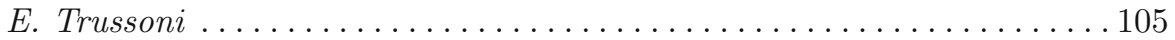

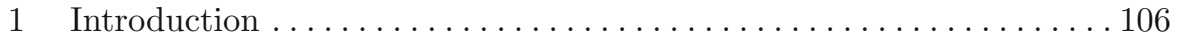

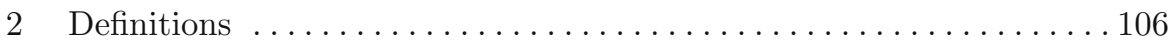

3 Equations and Mathematical Approach .................... 107

$4 \quad$ KHI: Linear Analysis . . . . . . . . . . . . . . . . . . . . . . . . . . 109

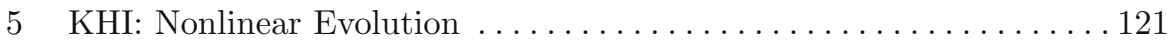

6 Conclusions.................................... 126

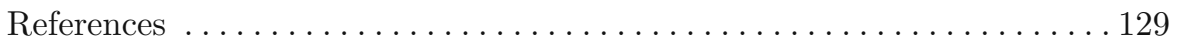




\section{Pressure-Driven Instabilities in Astrophysical Jets}

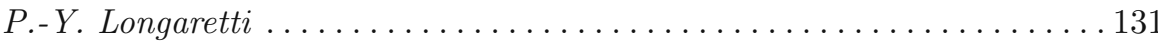

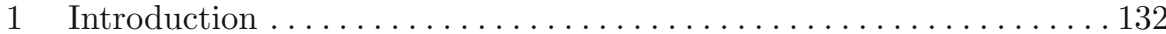

2 Heuristic Description of MHD Instabilities . . . . . . . . . . . . 134

3 Ideal MHD in Static Columns . . . . . . . . . . . . . . . . . . . 137

4 The Energy Principle and Its Consequences . . . . . . . . . . . . . . . . . . . 140

5 Dispersion Relation in the Large Azimuthal Field Limit . . . . . . . . . . . 142

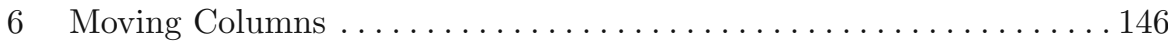

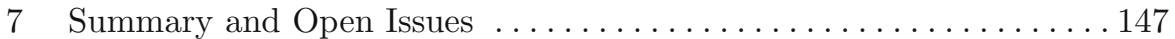

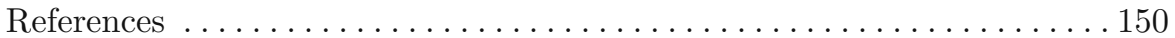

\section{Thermal Instabilities}

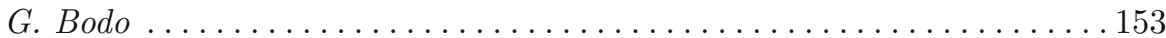

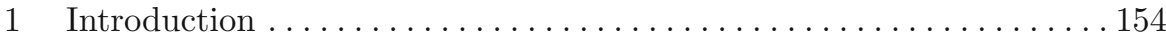

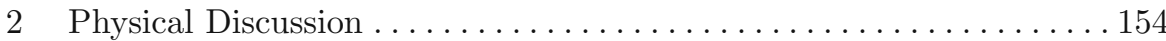

3 Linear Analysis . . . . . . . . . . . . . . . . . . . . . . . . . . 156

4 Influence of Radiative Losses on the KH Instability . . . . . . . . . . . . 161

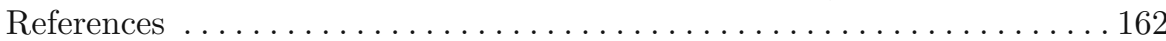

\section{The Oscillatory Instability of Radiative Shock Waves}

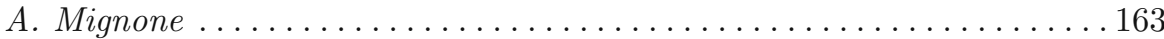

1 Introduction . . . . . . . . . . . . . . . . . . . . . . . . . 164

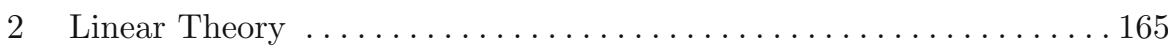

3 Nonlinear Dynamics ............................ 171

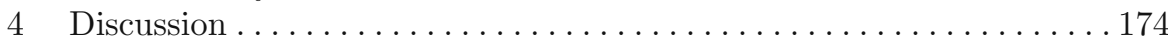

References ..................................... 175

Index . . . . . . . . . . . . . . . . . . . . . . . . 177 